\title{
A micromechanical model for deformation behavior of nanocrystalline copper
}

\author{
Jiaoxia Lan ${ }^{1, ~ a ~}$, Yongzhong $\mathrm{Wu}^{2, b}$ and Youshi Hong ${ }^{3, c}$ \\ ${ }^{1}$ General Courses Department, Academy of Military Transportation PLA, Tianjin, 300161, China \\ ${ }^{2}$ China North System Engineering Institute, Beijing ,100089, China \\ ${ }^{3}$ State Key Laboratory of Nonlinear Mechanics (LNM), Institute of Mechanics, Chinese Academy of \\ Sciences, Beijing, 100190, China \\ ajiaoxia_lan@yahoo.com.cn, ${ }^{b}$ wuyzcn@yahoo.com.cn, ${ }^{c}$ hongys@imech.ac.cn
}

Keywords: Nanocrystalline materials; Micromechanics; Strain energy; Pure copper

\begin{abstract}
Molecular dynamics simulations have show that nanocrystalline (NC) materials can be treated as composite materials consisting of two phases of grain and grain boundary. In this paper, the incremental stress-strain relation is derived based on deformation mechanism of NC materials and internal variable theory from micromechanics point of view. The developed model is exemplified by the pure copper subjected to uniaxial tension. Implicated iteration algorithm is then employed to obtain the stress-strain relation. Moreover, the effects of grain shape and statistical distribution of grain sizes are also discussed, and predicted results are compared with experimental values to verify the model.
\end{abstract}

\section{Introduction}

Nanostructured materials refer to those whose microstructure characteristic length or its geometrical size, at least one dimension, is in the nanometer range ${ }^{[1]}$. They have been the subject of considerable research in recent years due to their unique microstructure and appealing property.

Extensive experimental investigations ${ }^{[2-3]}$ and molecular dynamics simulation ${ }^{[4-9]}$ have show that $\mathrm{NC}$ materials can be considered as composite materials consisting of two phases of equiaxed grain and grain boundary. Due to smaller grains, the volume of grain boundary phase is comparable to the grain phase, so the role of grain boundary phase is not neglected regarding the mechanical properties compared with coarse grain materials. As we all know that the dislocation motion will ceased as the grain size decreases. So in this case, the dominant deformation mechanism is governed by grain boundary phase.

In this current investigation, $\mathrm{NC}$ materials are modeled as composites two phases of with grain and grain boundary. In order to calculate conveniently, we assume that both phases are isotropic, and the variation of temperature is neglected. The incremental stress-strain relation has been developed based on deformation mechanism of $\mathrm{NC}$ and internal variable theory. Then, the developed model was applied to pure copper subjected to uniaxial tension. The stress-strain relation predicted by the model and experimental data were also compared.

\section{Micromechanical Model}

It is assumed that the grains in NC materials are all spherical or spheroidal. When the grains are all spheroidal, we define the ellipsoidal domain as follows:

$\frac{x_{1}^{2}}{a_{1}^{2}}+\frac{x_{2}^{2}}{a_{2}^{2}}+\frac{x_{3}^{2}}{a_{3}^{2}} \leq 1$.

where $a_{i}(i=1,2,3)$ is one of the three semi-axes of the ellipsoid. Further, the grain shape is considered to be spheroidal when the condition $a_{2}=a_{3}=a \neq a_{1}$ is satisfied. The volume fraction of grains can be 
given by $v_{f}=\frac{(\beta a-w)(a-w)^{2}}{\beta a^{3}}$, where $\beta=a_{1} / a, a=d / 2 \sqrt[3]{\beta}, d$ is grain size, and $w$ is grain boundary thickness.

Consider a unit volume element subjected to plastic deformation, we can describe the state of material using strain tensor $\varepsilon_{i j}$, absolute temperature $T$ and internal variable $\varepsilon_{i j}^{p}$. From the point of thermodynamics ${ }^{[10,11]}$, the constitutive equation of the material and the evolution equation of internal variable are written as follows, respectively:

$$
\begin{gathered}
\sigma_{i j}=\frac{\partial \Xi}{\partial \varepsilon_{i j}}+\frac{1}{2}\left(\frac{\partial \Phi}{\partial \dot{\varepsilon}_{i j}} \dot{\varepsilon}_{i j}\right)^{-1} \Phi \frac{\partial \Phi}{\partial \dot{\varepsilon}_{i j}} . \\
\frac{\partial \Xi}{\partial \varepsilon_{i j}^{p}}+\frac{1}{2}\left(\frac{\partial \Phi}{\partial \dot{\vartheta}_{i j}} \dot{\vartheta}_{i j}\right)^{-1} \Phi \frac{\partial \Phi}{\partial \dot{\vartheta}_{i j}}=0 .
\end{gathered}
$$

In which $\Xi$ is total Gibbs free energy, and $\Phi$ is the dissipation function.

In comparison with coarse grain materials, the deformation mechanism of grain boundary phase can not be ignored. The yield function can be described as:

$$
f=\sqrt{J_{2}}-\frac{\sqrt{2}}{3}\left(\sigma_{y}+k_{y} d^{-0.5}\right)=0 \text {. }
$$

where $\sigma_{0}, k$ are material constants, and $J_{2}$ is second invariant of the stress deviator.

The grains with the plastic strain $\varepsilon_{i j}^{\mathrm{p}}$ are randomly distributed in the grain boundary phase. The strain filed caused by the applied force in the absence of plastic strain is denoted as $\varepsilon_{i j}^{0}$. According to Colonnett theory ${ }^{[12]}$, the total energy (Gibbs free energy) for the case of $\varepsilon_{i j}^{\mathrm{p}}$ and $\varepsilon_{i j}^{0}$ coexistence is the sum of energies for the conditions when the applied force and the plastic strain exist alone, respectively. So, the total Gibbs free energy can be written:

$$
\Xi=\frac{1}{2} \int_{D}\left(\sigma_{i j}^{0}+\sigma_{i j}^{\prime}\right)\left(\varepsilon_{i j}^{0}+\varepsilon_{i j}^{\prime}\right) d v-\frac{1}{2} v_{f} \sigma_{i j} \varepsilon_{i j}^{p}=\Xi=\frac{1}{2}\left(\sigma_{i j}^{0} \varepsilon_{i j}^{0}-v_{f} \sigma_{i j}^{0} \varepsilon_{i j}^{*}\right)-\frac{1}{2} v_{f} \sigma_{i j} \varepsilon_{i j}^{p} .
$$

where $\varepsilon_{i j}^{0}$ is applied strain, $\sigma_{i j}^{0}$ is the corresponding stress field if the elastic modulus of two phase are equal, $\sigma_{i j}^{\prime}, \varepsilon_{i j}^{\prime}$ are perturbations of the stress and strain fields, $\sigma_{i j}$ is the stress filed in the grain induced by plastic deformation, and $\varepsilon_{i j}^{*}$ is the fictitious eigenstrain introduced by the equivalent inclusion theory ${ }^{[12]}$. The expression of $\varepsilon_{i j}^{*}$ is as follows:

$\varepsilon_{i j}^{*}=\left[C_{i j m n}+\left(1-v_{f}\right)\left(C_{i j a b}-C_{i j a b}^{*}\right) S_{a b m n}\right]^{-1}\left(C_{m n k l}^{*}-C_{m n k l}\right) \varepsilon_{k l}^{0}$.

where $C_{i j k l}$ is elastic modulus tensor, and $S_{i j k l}$ is Eshelby's tensor ${ }^{[12]}$.

For isotropic materials, Eq. (5) can be rewritten as:

$\Xi=\frac{1}{2}\left(2 \bar{\mu} I_{i j k l}^{1}+\bar{\lambda} I_{i j k l}^{2}\right) \varepsilon_{i j}^{0} \varepsilon_{k l}^{0}-\frac{1}{2} v_{f} \sigma_{i j} \varepsilon_{i j}^{p}$.

where

$$
\begin{aligned}
& I_{i j k l}^{1}=\frac{1}{2}\left(\delta_{i k} \delta_{j l}+\delta_{i l} \delta_{j k}\right) . \\
& I_{i j k l}^{2}=\delta_{i j} \delta_{k l} .
\end{aligned}
$$




$$
\begin{aligned}
& \bar{\mu}=\mu-\frac{2 v_{f} \mu\left(\mu-\mu^{*}\right)}{A_{1}} . \\
& \bar{\lambda}=\lambda-v_{f}\left[\frac{2 \lambda\left(\mu-\mu^{*}\right)}{A_{1}}+2(\mu+\lambda)\left(\frac{\lambda-\lambda^{*}}{A_{1}}-\frac{2 A_{2}\left(\mu-\mu^{*}\right)}{A_{1}\left(A_{1}+3 A_{2}\right)}-\frac{3 A_{2}\left(\lambda-\lambda^{*}\right)}{A_{1}\left(A_{1}+3 A_{2}\right)}\right)\right] . \\
& A_{1}=2\left(1-v_{f}\right)\left(\mu^{*}-\mu\right) S_{1}+2 \mu . \\
& A_{2}=2\left(1-v_{f}\right)\left(\mu^{*}-\mu\right) S_{2}+\left(1-v_{f}\right)\left(\lambda^{*}-\lambda\right) S_{1}+3\left(1-v_{f}\right)\left(\lambda^{*}-\lambda\right) S_{2}+\lambda .
\end{aligned}
$$

with $\mu, \lambda, \mu^{*}, \lambda^{*}$ being Lame coefficients of grain boundary and grain phases, respectively, and $v$ being Poisson's ratio of grain boundary.

The total strain of the element can be expressed:

$\varepsilon_{i j}=\varepsilon_{i j}^{0}+\varepsilon_{i j}^{D}$.

where $\varepsilon_{i j}^{D}$ is volume average strain created by plastic deformation, and can be determined by equivalent inclusion theory ${ }^{[12]}$ :

$\varepsilon_{i j}^{D}=\varepsilon_{i j}^{p}-v_{f} B_{i j k l} \varepsilon_{k l}^{p}=\left(I_{i j k l}^{1}-v_{f} B_{i j k l}\right) \varepsilon_{k l}^{p}$.

where:

$$
\begin{aligned}
& B_{i j k l}=B_{1} I_{i j k l}^{1}+B_{2} I_{i j k l}^{2} . \\
& B_{1}=\frac{2 \mu^{*}}{C_{1}} . \\
& B_{2}=\frac{\lambda^{*}}{C_{1}}-\frac{2 \mu^{*} C_{2}}{C_{1}\left(C_{1}+3 C_{2}\right)}-\frac{3 \lambda^{*} C_{2}}{C_{1}\left(C_{1}+3 C_{2}\right)} . \\
& C_{1}=2\left[\mu^{*}+\left(1-v_{f}\right)\left(\mu^{*}-\mu\right)\left(S_{1}-1\right)\right] . \\
& C_{2}=\lambda^{*}+2\left(1-v_{f}\right)\left[2 S_{2}\left(\mu^{*}-\mu\right)+\left(S_{1}-1\right)\left(\lambda^{*}-\lambda\right)+3 S_{2}\left(\lambda^{*}-\lambda\right)\right] .
\end{aligned}
$$

By taking equivalent inclusion theory ${ }^{[12]}$, the stress field inside the grain induced by plastic deformation is derived as:

$\sigma_{i j}=D_{i j k l} \varepsilon_{k l}^{p}$.

where:

$$
\begin{aligned}
& D_{i j k l}=D_{1} I_{i j k l}^{1}+D_{2} I_{i j k l}^{2} . \\
& D_{1}=2\left(1-v_{f}\right) \mu\left(S_{1}-1\right) B_{1} . \\
& D_{2}=\left(1-v_{f}\right)\left\{2 B_{2} \mu\left(S_{1}-1\right)+\left(B_{1}+3 B_{2}\right)\left[2 \mu S_{2}+\lambda\left(S_{1}-1\right)+3 \lambda S_{2}\right] .\right.
\end{aligned}
$$

Substitution of Eqs.(14), (15),(21) into Eq.(7), we have:

$$
\Xi=\frac{1}{2}\left(2 \bar{\mu} I_{i j k l}^{1}+\bar{\lambda} I_{i j k l}^{2}\right)\left[\varepsilon_{i j}-\left(I_{i j m n}^{1}-v_{f} B_{i j m n}\right) \varepsilon_{m n}^{p}\right]\left[\varepsilon_{k l}-\left(I_{k l m n}^{1}-v_{f} B_{k l m n}\right) \varepsilon_{m n}^{p}\right]-\frac{1}{2} v_{f} D_{i j k l} \varepsilon_{i j}^{p} \varepsilon_{k l}^{p} .
$$

The energy dissipation in unit volume can be expressed as: 
$\Phi=\left(1-v_{f}\right) \sigma_{i j}^{c} \dot{\varepsilon}_{i j}^{p}$.

where $\sigma_{i j}^{c}$ satisfies the yield condition of Eq.(4).

Substitution of Eqs.(25), (26)into Eqs.(2), (3)respectively gives:

$$
\begin{aligned}
\dot{\sigma}_{i j} & =\left(2 \bar{\mu} I_{i j k l}^{1}+\bar{\lambda} I_{i j k l}^{2}\right)\left[\dot{\varepsilon}_{k l}-\left(I_{k l m n}^{1}-v_{f} B_{k l m n}\right) \dot{\varepsilon}_{m n}^{p}\right]=\bar{C}_{i j k l}\left[\dot{\varepsilon}_{k l}-\left(I_{k l m n}^{1}-v_{f} B_{k l m n}\right) \dot{\varepsilon}_{m n}^{p}\right] . \\
\sigma_{i j}^{c} & =\frac{\left[\left(I_{i j m n}^{1}-v_{f} B_{i j m n}\right) \sigma_{m n}+v_{f} D_{i j m n} \varepsilon_{m n}^{p}\right]}{1-v_{f}} .
\end{aligned}
$$

The criterion for loading can be written in the form:

$f\left(\sigma_{i j}^{c}\right)=0 \quad \frac{\partial f}{\partial \sigma_{i j}^{c}} \cdot \dot{\sigma}_{i j}^{c}>0$.

Substitution of Eq.(28) into Eq.(27), and using Eq.(29), then we have:

$$
\frac{\partial f}{\partial \sigma_{i j}^{c}}\left\{\left(I_{i j k l}^{1}-v_{f} B_{i j k l}\right) \bar{C}_{k l m n} \dot{\varepsilon}_{m n}+\left[v_{f} D_{i j m n}-\left(I_{i j k l}^{1}-v_{f} B_{i j k l}\right) \bar{C}_{k l a b}\left(I_{a b m n}^{1}-v_{f} B_{a b m n}\right)\right] \dot{\varepsilon}_{m n}^{p}\right\}=0 .
$$

Using Prandtl-Reuss flow rule ${ }^{[13]}$, the plastic strain rate can be written as:

$\dot{\varepsilon}_{m n}^{p}=\dot{\lambda} \frac{\partial f}{\partial \sigma_{m n}^{c}}$.

Substitution of Eq. (31) into Eq. (30) gives:

$\dot{\lambda}=\Lambda_{m n}^{m} \dot{\varepsilon}_{m n}$.

where:

$$
\Lambda_{m n}^{m}=\frac{\frac{\partial f}{\partial \sigma_{i j}^{c}}\left(I_{i j k l}^{1}-v_{f} B_{i j k l}\right) \bar{C}_{k l m n}}{\frac{\partial f}{\partial \sigma_{i j}^{c}}\left[\left(I_{i j k l}^{1}-v_{f} B_{i j k l}\right) \bar{C}_{k l a b}\left(I_{a b m n}^{1}-v_{f} B_{a b m n}\right)-v_{f} D_{i j m n}\right] \frac{\partial f}{\partial \sigma_{m n}^{c}}} .
$$

Accordingly, Substitution of Eq. (32) into Eq.(27), and the incremental stress-strain relation can be described as:

$$
\dot{\sigma}_{i j}=\bar{C}_{i j m n}\left(I_{m n k l}^{1}-\left(I_{m n a b}^{1}-v_{f} B_{m n a b}\right) \frac{\partial f}{\partial \sigma_{a b}^{c}} \Lambda_{k l}^{m}\right) \dot{\varepsilon}_{k l} .
$$

\section{Results}

The developed model was applied to pure copper subjected to uniaxial tension. The stress-strain relation of pure Copper was investigated. The calculated parameters ${ }^{[2]}$ are: $\mu^{*}=42.1 \mathrm{GPa}, v^{*}=0.3$, $\mu=25.26 \mathrm{GPa}, v=0.33$. The applied macro strain rate is $\dot{\varepsilon}^{0}=0.001 \mathrm{~s}^{-1}$. The comparison between the predicted results and experimental data ${ }^{[14,15]}$ is shown in Fig. 1. It is seen that they are in good agreement with each other.

The experiment results show that the stress-strain relation will take on a different phenomenon when the average grain size is the same. It may be provoked by the grain size distribution ${ }^{[16]}$. So we will discuss the influence of grain distribution. The grain distributions ${ }^{[17]}$ are shown in Fig. 2 . The effects of grain distribution on the stress strain relation are shown in Fig. 3. It is seen that the stress values are overestimated if grain distribution is not considered. 


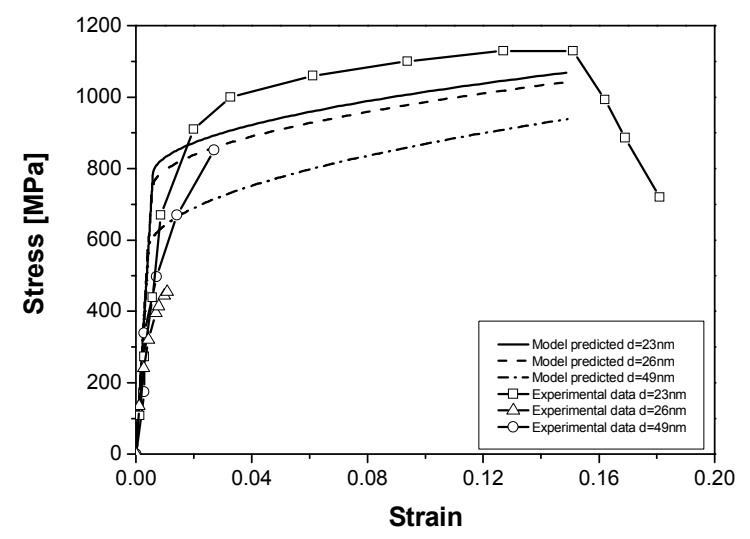

Fig. 1 Stress-strain relation predicted by present model in comparison with experimental data

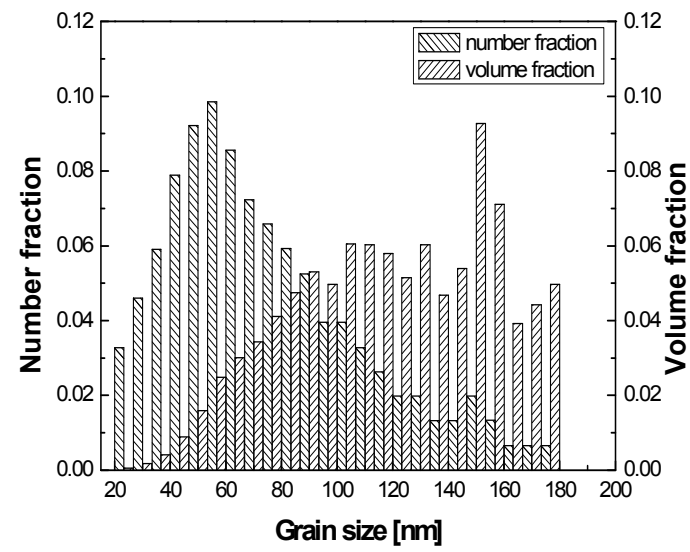

Fig. 2 Statistical distribution of grain size for $\mathrm{Cu}$ with average grain size of $\bar{d}=75 \mathrm{~nm}^{[17]}$

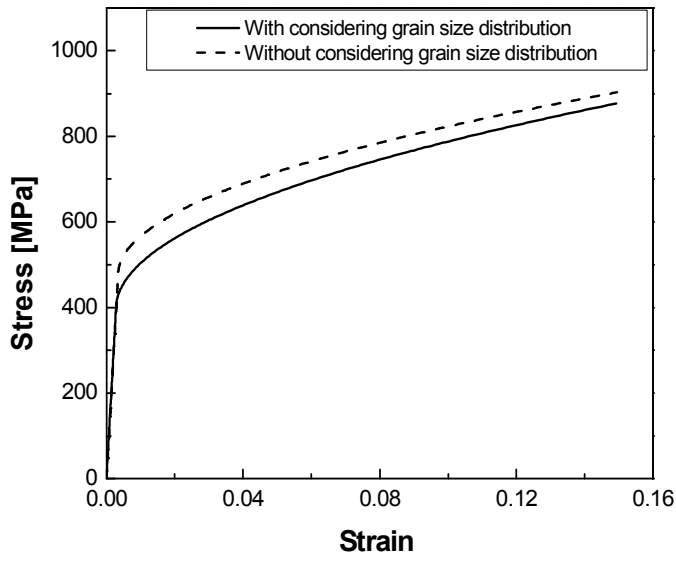

Fig.3 Stress-strain relation for average grain size of $\bar{d}=75 \mathrm{~nm}$.

The effects of parameter considering grain distribution are shown in Fig. 4 and 5. The same conclusions are taken on as without considering grain size distribution. The results show that the stress increases with the increasing parameter as $\beta \leq 1.0$, and it increases to the maximum at $\beta=1.0$, when parameter $\beta$ satisfies $\beta>1.0$, the stress increases with the increasing parameter $\beta$.

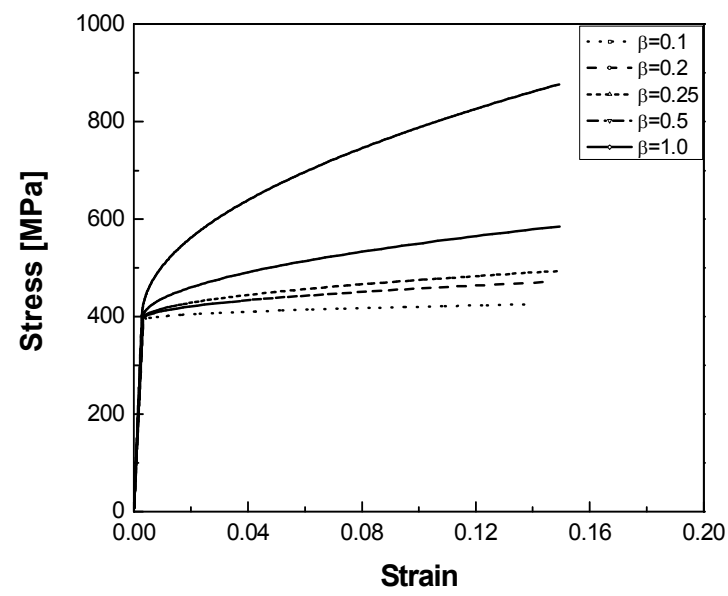

Fig. 4 Stress-strain relation for average grain size of $\bar{d}=75 \mathrm{~nm} \beta \leq 1.0$

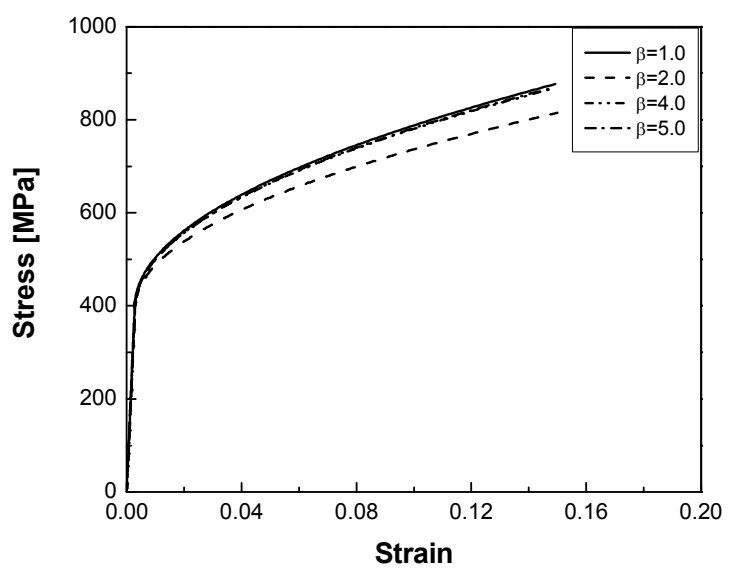

Fig. 5 Stress-strain relation for average grain size of $\bar{d}=75 \mathrm{~nm} \beta \geq 1.0$ 


\section{Conclusions}

The constitutive relation of NC materials is developed from the micromechanics point of view. Then, the developed model is applied in pure copper subjected to uniaxial tension. Taking into account grain shape and statistical distribution of grain sizes, the stress-strain relation has been obtained. The results derived from the model are compared with the experimental data in literature, and show that they are in good agreement with each other. The stress is relative small considering grain distribution. The grain shape has influence on the stress-strain relation without considering gain size distribution. Stress increases with the increasing parameter as $\beta \leq 1.0$, but decreases as $\beta>1.0$. When grain sizes distribution are considered, stress increases with parameter $\beta$, and arrives at the maximum as $\beta$ is 1.0 .

Acknowledgements This paper was supported by the National Nature Science Foundation of China (10772178, 10721202).

\section{References}

[1] H. Gleiter: Acta Mater. Vol. 48 (2000), p.1

[2] H.S. Kim, Y. Estrin, M.B. Bush: Acta Mater. Vol. 48 (2000), p. 493

[3] R. A.Valiev: Mat. Sci. Eng. Vol. A234-236 (1997), p.59

[4] J. Schiotz, Di Tolla FD, KW Jacobsen: Nature Vol. 39 (1998), p.561

[5] J Schiotz, KW Jacobsen: Science Vol. 301 (2003), p.1357

[6] H Van Swygenhoven, M Spaczer, A Caro: Acta Mater. Vol. 47 (1999), p.3117

[7] V Yamakov, D Wolf, SR Phillpot, H Gleiter: Acta Mater. Vol.50 (2002), p.61

[8] Yamakov V, Moldovan D, Rastogi K, Wolf D: Acta Mater. Vol. 54 (2006), p.4053

[9] M.A. Tschopp, D.L. McDowell: Scripta Mater. Vol. 58 (2008), p.299

[10] Z. Zirge: Introduction to thermomechanics. Amsterdam: North-Holland (1983)

[11] J. R. Rice: J. Mech. Phys. Solids Vol. 19 (1971), p.433

[12] T. Mura: Micromechanics of defects in solids. Martinus Nijhoff publishers, The Hague (1987)

[13] R Hill: The mathematical theory of plasticity, Oxford University Press, London (1950)

[14] Khaled M. Youssef, Ronald O. Scattergood, K. Linga Murty: Appl. Phys. Lett. Vol. 87 (2005), p.091904

[15] P. G. Sanders, J. A. Eastman, J. R. Weertman: Acta Mater. Vol. 45 (1997), p.4019

[16] Guang-Ping Zheng: Acta Mater. Vol. 55 (2007), p.149

[17] Y.H. Zhao, X.Z. Liao, Y.T. Zhu, Z. Horita and T.G. Langdon: Mater. Sci. Eng. Vol. A410-411 (2005), p.188 


\section{New Materials and Advanced Materials}

10.4028/www.scientific.net/AMR.152-153

\section{A Micromechanical Model for Deformation Behavior of Nanocrystalline Copper}

10.4028/www.scientific.net/AMR.152-153.772

\section{DOI References}

[1] H. Gleiter: Acta Mater. Vol. 48 (2000), p.1

doi:10.1016/S1359-6454(99)00285-2

[2] H.S. Kim, Y. Estrin, M.B. Bush: Acta Mater. Vol. 48 (2000), p. 493

doi:10.1016/S1359-6454(99)00353-5

[6] H Van Swygenhoven, M Spaczer, A Caro: Acta Mater. Vol. 47 (1999), p.3117

doi:10.1016/S1359-6454(99)00109-3

[7] V Yamakov, D Wolf, SR Phillpot, H Gleiter: Acta Mater. Vol.50 (2002), p.61

doi:10.1016/S1359-6454(01)00329-9

[8] Yamakov V, Moldovan D, Rastogi K, Wolf D: Acta Mater. Vol. 54 (2006), p.4053

doi:10.1016/j.actamat.2006.05.004

[9] M.A. Tschopp, D.L. McDowell: Scripta Mater. Vol. 58 (2008), p.299

doi:10.1016/j.scriptamat.2007.10.010

[11] J. R. Rice: J. Mech. Phys. Solids Vol. 19 (1971), p.433

doi:10.1016/0022-5096(71)90010-X

[14] Khaled M. Youssef, Ronald O. Scattergood, K. Linga Murty: Appl. Phys. Lett. Vol. 87 (2005), .091904 doi:10.1063/1.2034122

[15] P. G. Sanders, J. A. Eastman, J. R. Weertman: Acta Mater. Vol. 45 (1997), p.4019

doi:10.1016/S1359-6454(97)00092-X

[16] Guang-Ping Zheng: Acta Mater. Vol. 55 (2007), p.149

doi:10.1016/j.actamat.2007.06.013

[17] Y.H. Zhao, X.Z. Liao, Y.T. Zhu, Z. Horita and T.G. Langdon: Mater. Sci. Eng. Vol. A410-411 2005), p.188

doi:10.1557/JMR.2005.0057

[14] Khaled M. Youssef, Ronald O. Scattergood, K. Linga Murty: Appl. Phys. Lett. Vol. 87 (2005), p.091904 doi:10.1063/1.2034122

[17] Y.H. Zhao, X.Z. Liao, Y.T. Zhu, Z. Horita and T.G. Langdon: Mater. Sci. Eng. Vol. A410-411 (2005), p.188

doi:10.1557/JMR.2005.0057 